\title{
Endoscopic treatment of massive lower gastro- intestinal bleeding related to appendiceal stump
}

Massive lower gastrointestinal bleed from an appendiceal stump is rare. Most often bleeding is in the peritoneal cavity or the retroperitoneum, rarely in the cecum. To our knowledge, massive bleeding from an appendiceal stump occurring 3 weeks after laparoscopic appendectomy and successfully treated endoscopically has not been reported previously.

A 25-year-old man presented with the chief complaint of having passed fresh blood rectally for 1 day. He had passed a large amount of maroon-colored blood many times, associated with dizziness. He had undergone laparoscopic appendectomy 22 days earlier, with no complications, and had been discharged 2 days after surgery. In the emergency room his vital signs were unstable, and rectal examination revealed fresh blood.

Proctoscopy showed dark-colored blood mixed with clots. The patient's hemoglobin levels dropped by $7 \mathrm{~g} / \mathrm{dL}$ from baseline in 1 day and he received transfusion of 3 units of packed red blood cells. Colonoscopy revealed fresh blood in the colon, and in the cecum there was an ulcer at the appendicular orifice with oozing of fresh blood ( $\bullet$ Fig.1). Three hemoclips were deployed and hemostasis was achieved ( $\bullet$ Fig.2). The terminal ileum and the rest of the colon were normal. After colonoscopy the patient stopped passing fresh blood, and he was discharged 3 days after admission.

Complications after appendectomy happen early in the postoperative period and usually require reexploration $[1,2]$. Simsek et al. reported a case of appendiceal stump bleeding in a middle-aged man within 7 days of appendectomy [3]. Isolated Crohn's disease of the appendix, vascular ectasia, and appendiceal endometriosis have been reported as causes of lower gastrointestinal bleeding [4-6].

Bleeding from an ulcerated appendiceal stump should be suspected after an uncomplicated appendectomy in a patient

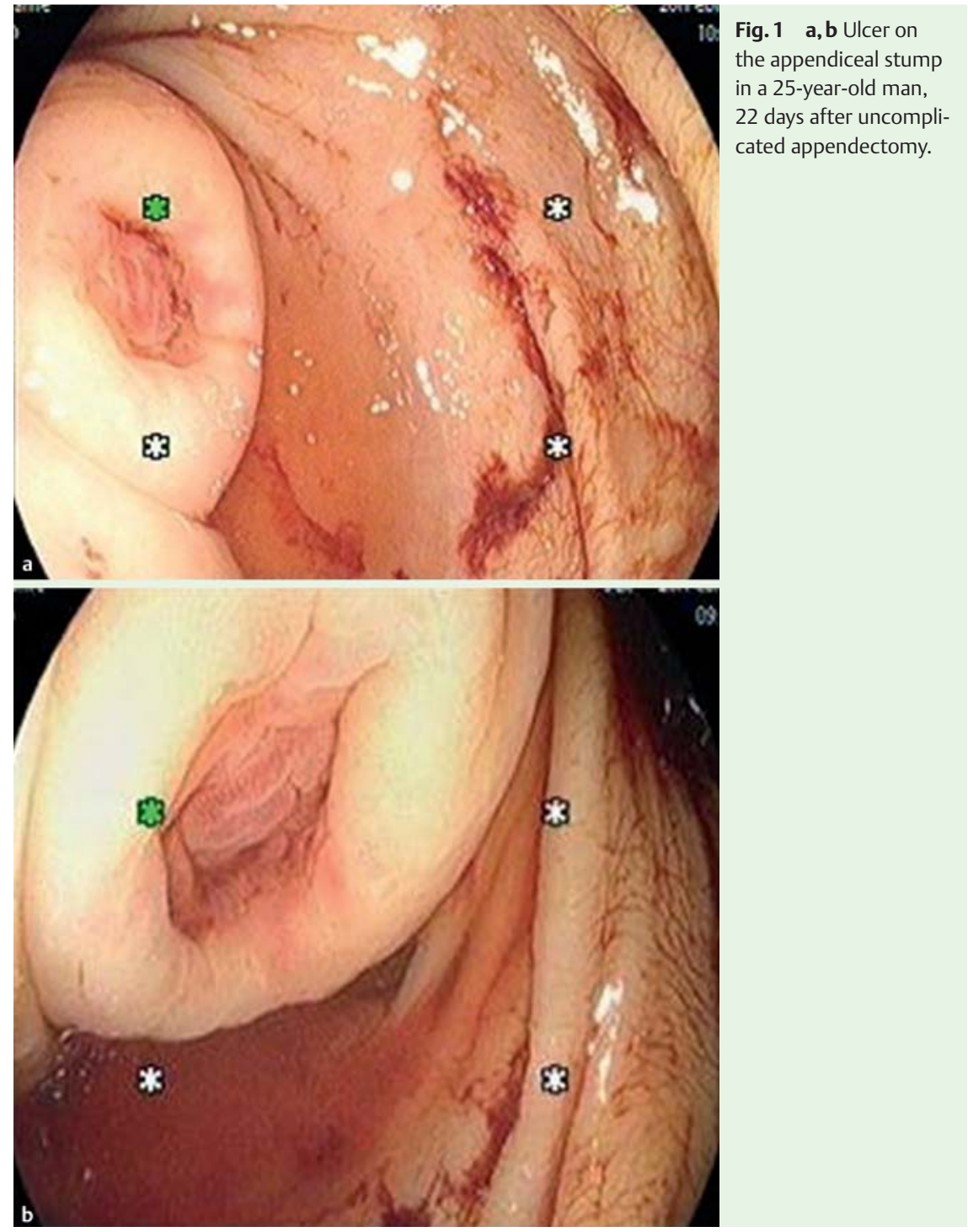

who presents with lower gastrointestinal bleeding. Endotherapy during colonoscopy should be tried as the initial method of hemostasis.

Endoscopy_UCTN_Code_CCL_1AD_2AF

Hamid Ullah Wani, A. O. Omosola, Shadi S. Mahmoud, Mohammad Tariq Butt, Saad R. Al Kaabi

Department of Medicine, Division of Gastroenterology, Hamad Medical Corporation, Doha, Qatar

\section{Competing interests: None}




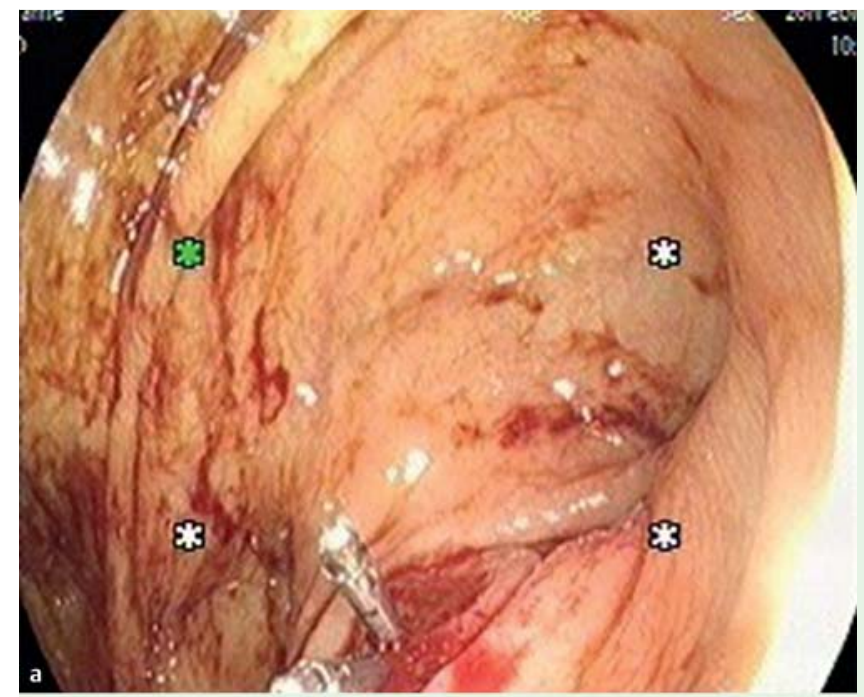

Fig. 2 a, b Ulcer with hemoclips.

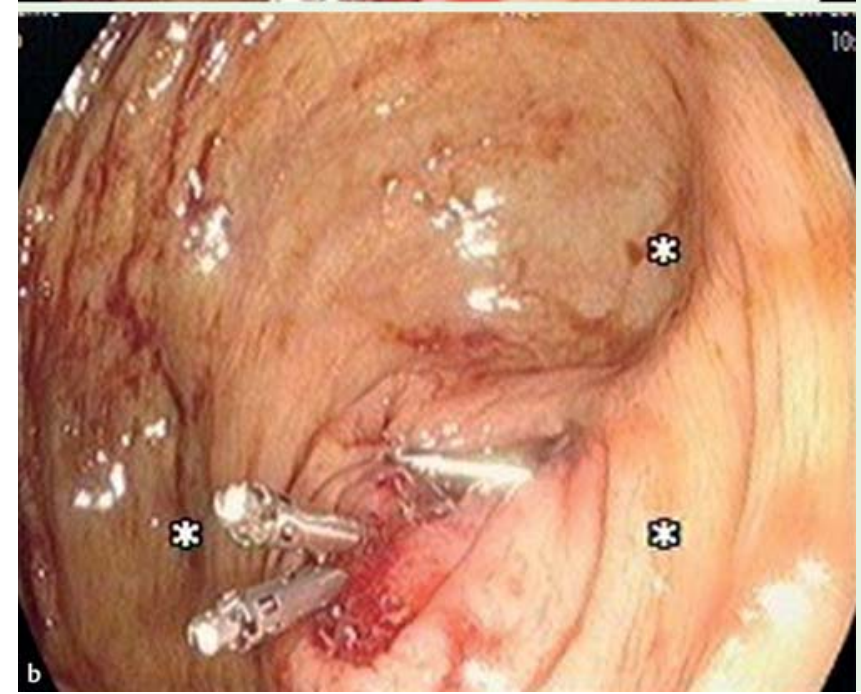

\section{References}

1 Khawaja FI. Diseases of the appendix recognized during colonoscopy. Saudi J Gastroenterol 2002; 8: 43-52

2 Pocard M, Chasserant P, Parc R. Massive rectal bleeding after appendectomy: report of 2 cases and review of the literature. Ann Chir 2002; 127: 703-705

3 Simsek Z, Karaahmet F, Yuksel $O$ et al. Successful endoscopic treatment of massive bleeding related to the appendiceal stump. Endoscopy 2013; 45 (Suppl. 02): E15

4 Morales TG, Yalam J, Dinning JP et al. Acute lower gastrointestinal bleeding from the appendix. Gastrointest Endosc 1997; 46: $458-460$

5 So JBY, Alexander DJ, Chong APY et al. Laparoscopic appendectomy in the management of acute lower gastrointestinal bleeding. Gastrointest Endosc 1995; 42: 488-489

6 Shome GP, Nagaraju M, Munis A et al. Appendiceal endometriosis presenting as massive lower intestinal hemorrhage. Am J Gastroenterol 1995; 90: 1881-1883

\section{Bibliography}

DOI http://dx.doi.org/

10.1055/s-0034-1365383

Endoscopy 2015; 47: E225-E226

(c) Georg Thieme Verlag KG

Stuttgart · New York

ISSN 0013-726X

\section{Corresponding author}

\section{Hamid Ullah Wani, MD}

Hamad Medical Corporation

Division of Gastroenterology

Endoscopy 2 South 2

Doha 3050

Qatar

Fax: +974-4392519

drhamidwani@gmail.com 